\title{
Callum G. BROWN, Religion and Society in Twentieth-Century Britain
}

London, Pearson, Longman, 2006, 344 p.

\section{Jean-Louis Ormières}

\section{(2) OpenEdition} Journals

Édition électronique

URL : http://journals.openedition.org/assr/21538

DOI : $10.4000 /$ assr.21538

ISSN : 1777-5825

Éditeur

Éditions de l'EHESS

Édition imprimée

Date de publication : 31 décembre 2009

Pagination : $75-342$

ISBN : 978-2-7132-2218-4

ISSN : 0335-5985

Référence électronique

Jean-Louis Ormières, "Callum G. Brown, Religion and Society in Twentieth-Century Britain », Archives de sciences sociales des religions [En ligne], 148 | octobre-décembre 2009, document 148-29, mis en ligne le 27 janvier 2010, consulté le 21 septembre 2020. URL : http://journals.openedition.org/assr/ 21538 ; DOI : https://doi.org/10.4000/assr.21538

Ce document a été généré automatiquement le 21 septembre 2020.

(C) Archives de sciences sociales des religions 


\section{Callum G. BROWN, Religion and Society in Twentieth-Century Britain}

London, Pearson, Longman, 2006, 344 p.

Jean-Louis Ormières

\section{RÉFÉRENCE}

Callum G. BROWN, Religion and Society in Twentieth-Century Britain, London, Pearson,

Longman, 2006, $344 \mathrm{p}$.

1 Consacré à l'évolution des rapports entre religion et société au Royaume-Uni du début $\mathrm{du} \mathrm{XIX}^{\mathrm{e}}$ siècle à nos jours, ce livre est une contribution supplémentaire à la vive controverse qui sévit depuis plusieurs décennies outre-Manche concernant la sécularisation. Refusant de rejoindre les tenants d'une approche «révisionniste» qui ont mis en avant le caractère non linéaire du processus de "sortie de la religion", l'historien Callum G. Brown se distingue également des défenseurs de la théorie classique qui fait de la sécularisation une conséquence évidente de l'industrialisation, de l'urbanisation et de la modernité. Comme dans son ouvrage précédent (The Death of Christian Britain, 2001), C.Brown montre que c'est à partir des années soixante que se situe en Grande-Bretagne la véritable rupture entre une société imprégnée de culture chrétienne et une société sécularisée.

2 Moment fondamental, comme en témoigne les diverses sources statistiques (croyance en Dieu, pratique, mœurs), les «sixties» s'inscrivent dans un siècle que Brown admet être un siècle «sécularisateur». Si, en 1900, la plupart des Britanniques s'accordaient à considérer que leur nation était chrétienne, un siècle plus tard, ils sont tout aussi nombreux à la juger sécularisée. Brown ne manque cependant pas de faire observer que, tout au long de ce siècle, la nature de la religion, comme le sens attribué au mot «sécularisation» ont évolué. 
3 S'appuyant sur des documents bruts émanant du corps ecclésiastique mais plus encore des laïcs, les six autres chapitres scandent ce siècle sécularisateur. Le premier aborde l'héritage victorien et décrit une société chrétienne dans laquelle hommes et femmes se voient dotés d'attributs religieux très distincts, la femme devant être un modèle de vertus (piété, pureté, chasteté, etc.) tandis que l'homme serait porteur de tous les vices. C'est l'effondrement de ces modèles qui sera précisément l'un des moteurs de la brusque accélération du processus de sécularisation au cours des années soixante. Même si, à la différence de ce qui se passe en France et en Allemagne, l'incroyance ne parvient pas à prendre son envol, des changements sont toutefois perceptibles tant au niveau intellectuel (développement du rationalisme et du positivisme) qu'en ce qui concerne les rapports entre religion et politique du fait de la montée de l'individualisme et du socialisme.

4 Le deuxième chapitre analyse l'impact de la Première Guerre mondiale sur cette société religieuse. L'incorporation des femmes dans les industries de guerre aurait été en mesure de bousculer les stéréotypes traditionnels entre les sexes mais l'institution ecclésiale déploya des efforts importants pour contrer cette évolution. En définitive, ce qu'il faut retenir de cette période au cours de laquelle vont se développer le mouvement des suffragettes, d'une part, le socialisme d'autre part, c'est une crise de l'autorité sociale. Mais si le système de classe est quelque peu bousculé, la foi chrétienne perdure.

5 Reste qu'au cours de l'entre-deux-guerres, la culture chrétienne est quelque peu brouillée. Au sortir de la guerre, on assiste à un regain de puritanisme. Le mouvement évangéliste lance une vaste campagne contre l'alcoolisme. Gardienne morale de la famille, la femme est placée au centre de cette campagne, confortant une fois encore la division traditionnelle des sexes. Cette campagne eut néanmoins pour effet de déstabiliser la hiérarchie ecclésiastique. Sur plusieurs points la rigueur religieuse semble s'affaiblir. Par ailleurs, l'Église d'Angleterre devait faire face à d'importantes divisions entre évangéliques, ritualistes et libéraux et, en Écosse comme au Pays de Galles, les liens entre l'État et l'Église se distendent. Enfin, la crise économique suscite de vives tensions sociales. Malgré tout, la religiosité des classes laborieuses reste encore très élevée.

6 La période d'austérité consécutive à la guerre (1945-1959) s'accompagne d'une intensification du conservatisme moral. On attend plus que jamais que le citoyen se comporte en chrétien. Plus pratiquantes que les hommes, les femmes demeurent comme par le passé les gardiennes de la rigueur morale. Les faibles chiffres de l'illégitimité confirment l'austérité du climat moral et religieux de l'époque. Le succès de la croisade du prédicateur américain Billy Graham, en 1954, souligne la vitalité de la demande religieuse. Pourtant, dès la fin de la décennie cinquante, les signes avantcoureurs de la crise à venir, notamment la perte de religion chez les jeunes, sont présents. Plus que la religion, c'est le conservatisme, les rôles traditionnels des sexes et l'autorité qui sont alors l'objet de ce que l'auteur appelle «l'assaut social». Mais la culture chrétienne va en être la première victime.

7 C'est donc la décade des «sixties» (1960-1973) qui demeure le grand moment du déclin de la religion dans l'histoire britannique. La pop musique, la mode radicale et la révolte étudiante sont les agents d'un profond changement dans les attitudes sexuelles et du rejet de l'autorité sociale conventionnelle. Cette révolution culturelle et la révolution sexuelle qui l'accompagne affectent tout particulièrement les jeunes et les femmes. La 
libéralisation, la diversité et la liberté du choix individuel en matière de mœurs mettent en péril la religion. En quelques années, le nombre de baptêmes et de confirmations s'effondre, de même que celui des ordinations. Plus ou moins selon les régions, la pratique chute également.

Objet d'un ultime chapitre, le dernier quart de siècle témoigne de l'accentuation, plus ou moins prononcée selon les régions, de la marginalisation de la religion dans la vie publique britannique. L'affaiblissement de la culture chrétienne chez les jeunes se poursuit. Chez les anglicans comme chez les catholiques, le déclin de la pratique et des ordinations ne faiblit pas. Les jeunes couples sont de plus en plus nombreux à refuser de se marier à l'église. Enfin, la progression du nombre des naissances hors mariage connaît une brusque accélération passant de $10 \%$ en 1980 à $40 \%$ à la fin du siècle. Conséquence d'une forte immigration en provenance de ses anciennes colonies, la Grande-Bretagne est devenue aujourd'hui une société pluri-religieuse, ce qui n'est pas sans incidence sur la religion «historique» comme sur les autres (islam, hindouisme, etc.) Ce pluralisme religieux alimente, pour chacune des religions, d'une part le processus de sécularisation, d'autre part la montée des fondamentalismes. Mais C.Brown considère que ceux-ci ne seront pas en mesure de remettre en cause celui-là.

9 La diversité des sources utilisées par C.Brown, en particulier la presse et les témoignages oraux, rend convaincante une démonstration qui refuse de s'en tenir aux seules statistiques. On regrettera toutefois que n'ait pas été plus approfondie l'idée signalée ici ou là (p.112 et p.225) selon laquelle la religion chrétienne aurait été victime surtout d'un rejet plus général de toute autorité par la génération des années soixante. 